REVIEW ARTICLE

J.M. Johnson

G. Moonis

G.E. Green

R. Carmody

H.N. Burbank

\section{Syndromes of the First and Second Branchial Arches, Part 1: Embryology and Characteristic Defects}

\begin{abstract}
SUMMARY: A variety of congenital syndromes affecting the face occur due to defects involving the first and second BAs. Radiographic evaluation of craniofacial deformities is necessary to define aberrant anatomy, plan surgical procedures, and evaluate the effects of craniofacial growth and surgical reconstructions. High-resolution CT has proved vital in determining the nature and extent of these syndromes. The radiologic evaluation of syndromes of the first and second BAs should begin first by studying a series of isolated defects: $C L$ with or without $C P$, micrognathia, and EAC atresia, which compose the major features of these syndromes and allow more specific diagnosis. After discussion of these defects and the associated embryology, we proceed to discuss the VCFS, PRS, ACS, TCS, Stickler syndrome, and HFM.
\end{abstract}

$\mathbf{R}$ adiographic evaluation of craniofacial deformities is necessary to define aberrant anatomy, plan surgical procedures, and evaluate the effects of craniofacial growth and surgical reconstructions. ${ }^{1}$ The recent rapid proliferation of MDCT is due, in part, to the increased utility of this technique for multiplanar bone and soft-tissue imaging. The definition of fine bony structure of the craniofacial anatomy on CT images is unmatched by other modalities. There has also been increased demand for treatment planning along with the advances in high-resolution CT evaluation and $3 \mathrm{D}$ reconstruction techniques.

Knowledge of the genetic basis of human disease and its effect on embryologic development has expanded greatly in recent years. Disorders of the first and second BA are generally thought to result from a combination of inadequate migration and inadequate formation of facial mesenchyma. Because many structures of the head and neck migrate during fetal development, an understanding of embryologic development helps determine the origin and nature of congenital lesions. Familiarity with craniofacial embryology and its associated effects on resultant anatomy also leads to a better understanding of the pathophysiologic basis of craniofacial syndromes. Additionally, it helps to establish a search pattern for characteristic radiologic features of many of these anomalies.

Part 1 of this review establishes the embryology, developmental anatomy, clinical symptoms, and characteristic imaging features of the isolated defects that compose some of the

From the Division of Neuroradiology (J.M.J.. H.N.B.), Department of Radiology, Fletcher Allen Health Care, Burlington, Vermont; Division of Neuroradiology (G.M.), Department of Radiology, Beth Israel Deaconess Medical Center and Mass Eye and Ear Infirmary, Harvard Medical School, Boston, Massachusetts; Department of Pediatric Otolaryngology (G.E.G.), University of Michigan, Ann Arbor, Michigan; and Division of Neuroradiology (R.C.), Department of Radiology, University of Arizona, Tucson, Arizona.

Please address correspondence to Jason M. Johnson, MD, Department of Radiology, 111 Colchester Ave, Burlington, VT 05401; e-mail: Jason.Johnson@vtmednet.org

Indicates open access to non-subscribers at www.ajnr.org

DOI 10.3174/ajnr.A2072 major features of the syndromes of the first and second BAs. Part 2 of this review discusses the syndromes and their radiographic features: PRS, HFM, ACS, TCS, Stickler syndrome, and VCFS. When applicable, the disorders number of the public data base of bibliographic information about human genes and genetic disorders - the Online Mendelian Inheritance in Man (http://www.ncbi.nlm.nih.gov/omim)—is given.

\section{Imaging Approaches and Techniques}

$\mathrm{CT}$ is the imaging technique of choice for studying syndromes of the first and second BAs. Modern MDCT scanners offer the additional ability to reconstruct facial bone data for dedicated evaluation of the middle and inner ear. We recommend acquiring images in the axial plane and reformatting sagittal and coronal high-resolution CT scans through the midface in planes parallel and perpendicular to the hard palate. Images should be obtained axially with a bone algorithm at a section thickness and interval of $\leq 3.0 \mathrm{~mm}$. We recommend a $1.5-\mathrm{mm}$ section thickness obtained by using a helical technique with $50 \%$ overlap of sections. Intravenous contrast may be administered in surgical planning to evaluate the aberrant course of the internal carotid artery but is typically not necessary. 3D CT reconstruction often allows a unified appreciation of abnormalities, which may aid in the detection of abnormalities and formulation of differential diagnoses. The complex interrelationship of malformations seen in craniofacial syndromes is often not adequately conveyed on axial and nonaxial planar reformations. ${ }^{1} 3 \mathrm{D}$ imaging provides clinicians, radiologists, and patients with a quick easy-to-understand overview of craniofacial structures. These $3 \mathrm{D}$ representations can also be used for life-size model formation that can be used in surgical planning.

\section{Embryology of the First and Second BAs and Associated Structures}

Development of the craniofacial structures is a complex process that proceeds in an orderly fashion throughout embryonic and fetal stages of formation. Craniofacial growth occurs 


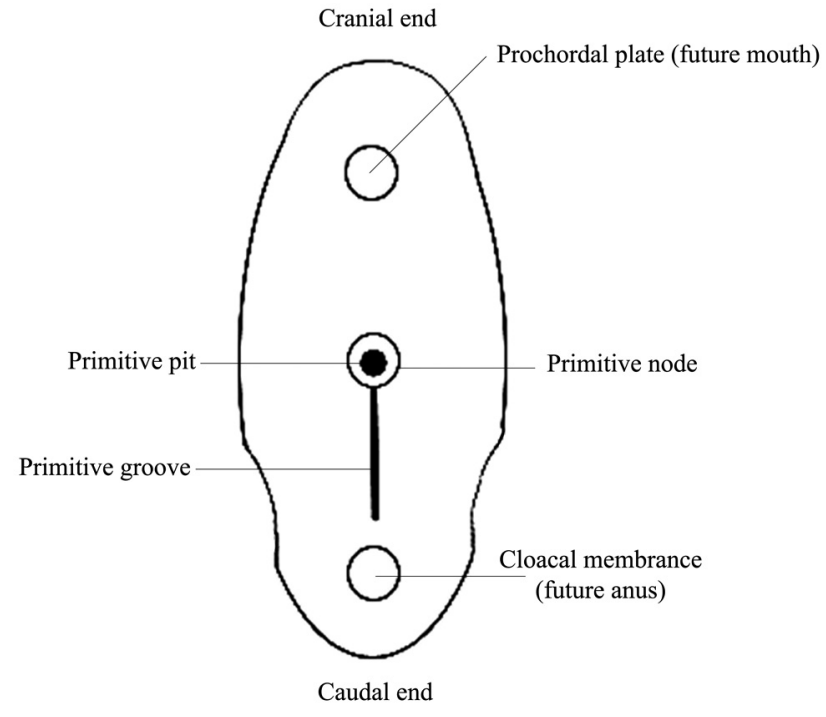

Fig 1. Dorsal aspect of the germ disk from an approximately 15-day embryo.

due to a relatively rapid and orderly composition of mesodermal and cranial neural crest cells via a complex signaling network. Syndromes of the first and second BAs manifest along a spectrum of hypoplasia and aplasia of the structures composing these arches. Some differences between abnormalities of the first and second BA derivatives may reflect differences in the embryologic age at the time of the insult with respect to neural crest cell migration. Other changes are related to deregulation of cell-signaling pathways triggered by a combination of genetic and environmental factors. ${ }^{2}$ The manifestation and severity of the congenital abnormality depend on the alteration of gene-expression profiles. ${ }^{2,3}$ The pluripotent nature of synchronously migrating cells is thought to, at least partially, explain the appearance and pattern of mesenchymal and epithelial abnormalities seen with syndromic defects of the BAs. Multiple craniofacial syndromes have been shown to result from an abnormality in the quantity or quality of neural crest cell migration (ie, TCS and VCFS).,

The 3 primary germ layers, ectoderm, mesoderm, and endoderm, form on the embryonic trilaminar germ disk and are the basis of all tissue and organ formation. The prechordal plate at the cranial end and the cloacal plate at the caudal end characterize the embryonic poles of the germ disk, which form due to opposing zones of deficient mesoderm (Fig 1). The prechordal plate is formed by the sinking inward of the oropharyngeal membrane. This creates a central depression for a key central structure in the formation of the face, the stomodeum. The frontal prominence develops superior to the stomodeum during the fourth postovulatory week and gives rise to the superior and middle portions of the face, comprising the area between the upper lip and forehead. ${ }^{6,7}$ The maxillary and nasal swellings form beneath the frontal prominence. Synchronously with the formation of the nasofrontal prominence, there is formation of 6 mesodermal arches that are separated from each other externally by ectodermally lined branchial clefts (grooves) and internally by endodermally lined pharyngeal pouches (Fig 2). ${ }^{8}$

Although development of pharyngeal arches, clefts, and pouches resembles formation of gills in fish and amphibia, in

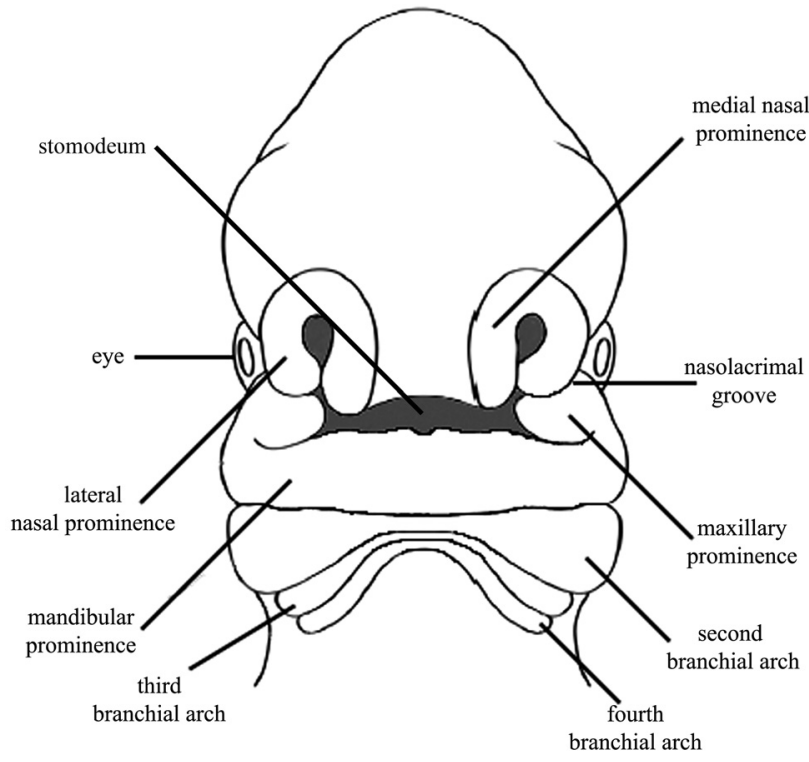

Fig 2. Frontal view of an approximately 30-day embryo showing the positions of the stomodeum relative to the medial and lateral nasal prominence and the maxillary and mandibular prominences.

the human embryo, real gills (branchia) are never formed. The term pharyngeal has been alternatively offered for use in the human embryo; however, "branchial" continues to be the more commonplace term and thus is used in this article. ${ }^{9}$ The BAs have a significant impact on the external appearance of vertebrates. Originally, they consist of slabs of mesenchymal tissue divided by the branchial clefts. At the end of the fourth week of gestation, 4 well-defined pairs of BAs contribute to the characteristic external appearance of the human embryo. ${ }^{7,10}$

The mandibular prominence of the first arch lies caudal to the stomodeum. The maxillary prominence represents the dorsal portion of the first BA and is located lateral to the stomodeum and the frontonasal prominence. The mesenchyme of the maxillary process gives rise to the maxilla, zygomatic bone, and a part of the temporal bone through membranous ossification. The mandible is also formed by membranous ossification of mesenchymal tissue surrounding the Meckel cartilage, the cartilaginous mesenchymal component of the first $\mathrm{BA}$. The first BA additionally gives rise to the muscles of mastication, the short crus and body of the incus and the head of the malleus, parts of the auricle, the anterior two-thirds of the tongue, and the mandibular branch of the trigeminal nerve.

The second or hyoid arch enlarges and grows so that by the sixth week, it will overlap and cover the third, fourth, and sixth arches. The Reichart cartilage is the mesenchymal contribution to the second arch that forms the styloid ligament; the manubrium of the malleus; the long process of the incus; the head, neck, and the crura of the stapes; and portions of the body and the lesser horn of the hyoid bone. The second arch also contributes the muscles of facial expression, the stapedius, the stylohyoid, and the posterior belly of the digastric muscle. These muscles are innervated by the facial nerve, though they migrate into the territory of the first BA. ${ }^{10-13}$

Specific neural crest cell segregation is critical to prevent fusions of the ectodermal and mesenchymal elements and also to prevent mixing of neural crest cells with different genetic constitutions. ${ }^{3}$ This migrational isolation leads each pharyn- 


\begin{tabular}{|c|c|c|c|c|}
\hline Location & Cleft & Arch & Nerve & Pouch \\
\hline First & $\begin{array}{l}\text { External ear } \\
\text { canal }\end{array}$ & $\begin{array}{l}\text { Mandible, muscles of mastication, 5th cranial } \\
\text { nerve, malleus, and incus }\end{array}$ & Trigeminal nerve (V2 and V3) & $\begin{array}{l}\text { Eustachian tube, tympanic cavity, } \\
\text { mastoid air cells }\end{array}$ \\
\hline Second & $\begin{array}{l}\text { Cervical sinus } \\
\text { of His }\end{array}$ & $\begin{array}{l}\text { Muscles of facial expression, body and lesser } \\
\text { horns of hyoid, 7th and 8th cranial nerves, } \\
\text { stapes }\end{array}$ & Facial nerve (VII) & Palatine tonsil \\
\hline Third & $\begin{array}{l}\text { Cervical sinus } \\
\text { of His }\end{array}$ & $\begin{array}{l}\text { Superior constrictor muscles, internal carotid } \\
\text { artery, 9th cranial nerve, greater horn, and } \\
\text { body of hyoid }\end{array}$ & Glossopharyngeal nerve (IX) & $\begin{array}{l}\text { Inferior parathyroid, thymus, } \\
\text { pyriform fossa }\end{array}$ \\
\hline Fourth & $\begin{array}{l}\text { Cervical sinus } \\
\text { of His }\end{array}$ & $\begin{array}{l}\text { Thyroid and cuneiform cartilages, 10th cranial } \\
\text { nerve, aortic arch and right subclavian } \\
\text { artery, part of laryngeal muscles }\end{array}$ & $\begin{array}{l}\text { Vagus nerve }(X) \text {, superior } \\
\text { laryngeal nerve }\end{array}$ & $\begin{array}{l}\text { Superior parathyroid, apex of } \\
\text { pyriform sinus }\end{array}$ \\
\hline $\begin{array}{l}\text { Fifth and } \\
\text { sixth }\end{array}$ & None & $\begin{array}{l}\text { Portions of the laryngeal muscles and } \\
\text { skeleton, inferior pharyngeal constrictor } \\
\text { muscles, 11th cranial nerve }\end{array}$ & $\begin{array}{l}\text { Vagus nerve }(X) \text {, recurrent } \\
\text { laryngeal nerve }\end{array}$ & $\begin{array}{l}\text { Parafollicular "C" cells of thyroid } \\
\text { gland }\end{array}$ \\
\hline
\end{tabular}

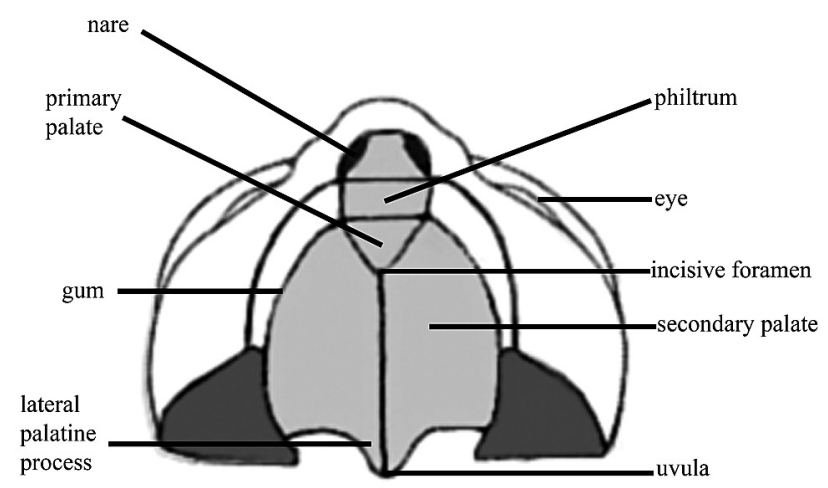

Fig 3. Ventral illustration of the palate, incisive foramen, gum, lip, and nose.

geal arch to consist of a core of specific mesenchymal tissue covered on the outside by surface ectoderm and on the inside by epithelium of endodermal origin. The core of each arch comprises neural crest cells that migrate along the BAs, helping to form the characteristic muscular, cranial nerve, and arterial component of each arch (Table 1). ${ }^{7,10,14,15}$

The philtrum and primary palate, the structures anterior to the incisive foramen, begin to form at approximately 5 weeks of gestational age by the coalition, growth, and differentiation of the frontonasal process and the fusion of the 2 medial nasal prominences. The fusion of medial nasal prominences gives rise to the intermaxillary segment of the frontonasal process. This structure is the origin of the philtrum and the portion of the maxilla from which the incisors arise. During the fifth and sixth gestational weeks, medial growth of the maxillary prominences results in fusion of the medial nasal and maxillary prominences. This leads to formation of the upper lip and anterior alveolus (Fig 3). The most common type of cleft lip results from failure of the maxillary swellings to fuse with the intermaxillary process. ${ }^{7,16-18}$

Formation of the secondary palate parallels that of the primary palate. The secondary palate, the portion posterior to the incisive foramen, forms through the fusion of paired outgrowths of the maxillary prominences, the palatal shelves. The shelves appear during the sixth week of development as vertical projections into the oral cavity on the lateral aspects of the tongue. In the seventh week of gestational development, the shelves elevate to a horizontal orientation and fuse, closing the secondary palate. Fusion begins anteriorly at the incisive fora- men and proceeds posteriorly to completion around the 12th gestational week. Failure of complete closure of this process or complete elevation of the palatal shelves leads to CP. The tongue does not directly participate in palate closure; however, altered tongue position or function may mechanically block fusion of the palatal shelves, as seen in PRS, and can occur in cases of severe micrognathia and syndromes associated with poor neuromuscular control (ie, Trisomy 21). ${ }^{19-22}$

\section{Isolated Defects}

The radiologic evaluation of syndromes of the first and second BAs should begin with studying a series of isolated defects that compose some of the major features of these syndromes and allow a more specific diagnosis.

\section{Facial Clefting}

Facial clefting, CL with or without $\mathrm{CP}$, is a common congenital malformation, accounting for $13 \%$ of all congenital anomalies, second only to clubfoot as the most frequent major birth anomaly. ${ }^{23}$ It is the most common congenital craniofacial malformation. ${ }^{24}$ Prevalence of $\mathrm{CL} / \mathrm{P}$ averages approximately 1 in 700 , with variations among races and between genders. ${ }^{25}$ Although in many neonates, $\mathrm{CL} / \mathrm{P}$ is isolated, $29 \%$ may be associated with an underlying disorder. ${ }^{26,27} \mathrm{CL} / \mathrm{P}$ is associated with $>300$ syndromes including ACS, TCS, PRS, Goldenhar syndrome, Stickler syndrome, and VCFS. ${ }^{16,27,28}$

Facial clefting has a major clinical impact, requiring surgical, dental, orthodontic, speech, hearing, and psychological management throughout childhood. The etiology of CL/P is mostly unknown, but both genetic and environmental factors play a role. ${ }^{29}$ There is marked racial and geographic variability observed, with a higher prevalence seen among Native Americans (3.6 per 1000) and a lower frequency among African Americans (0.5 per 1000). CL/P is etiologically distinct from $\mathrm{CP}$ alone. First-degree relatives of patients with $\mathrm{CL} / \mathrm{P}$ have an increased incidence of CL/P but not of CP alone. Relatives of patients with $\mathrm{CP}$ alone have an increased frequency of $\mathrm{CP}$ but not of $\mathrm{CL} / \mathrm{P} .^{30}$

Failure of fusion between any of the facial structures (eg, failure of maxillary swellings to fuse with the intermaxillary process leading to cleft; see discussion above) results in a cleft, which may be unilateral or bilateral. Clefting of the lip and palate is seen along a spectrum, extending from occult discontinuities within the orbicularis oris muscle, which may be de- 

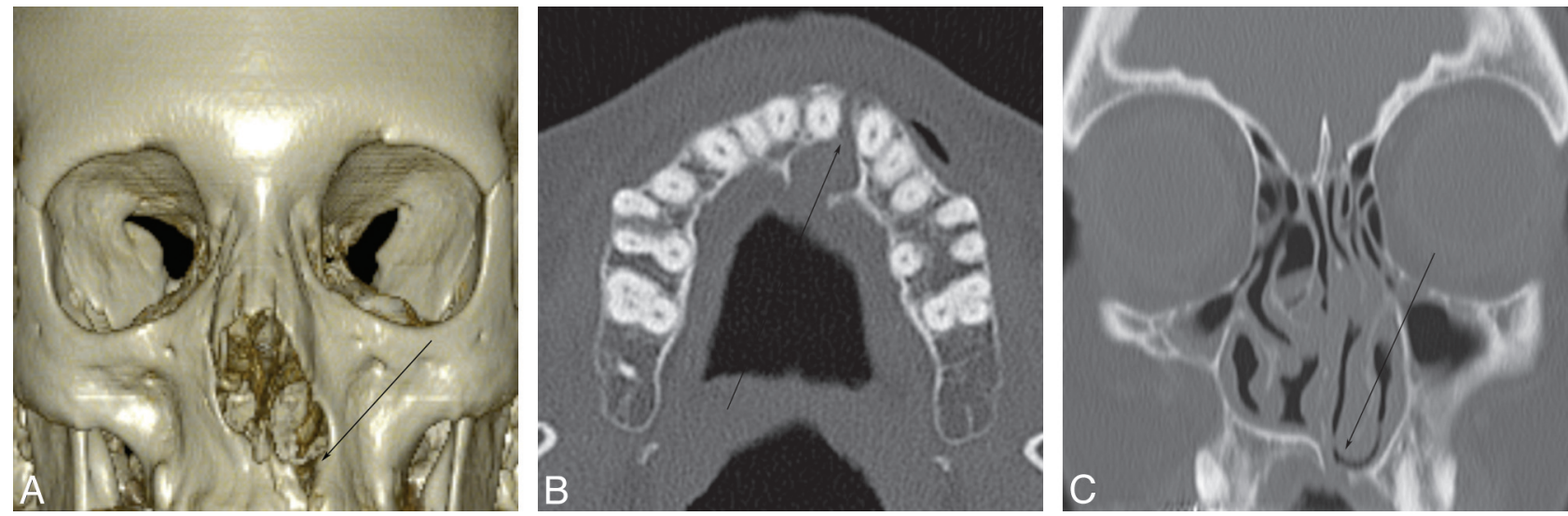

Fig 4. A, A 44-year-old woman with CP. 3D bony reconstruction shows a bony cleft (arrow) extending from the left aspect of an asymmetrically enlarged pyriform aperture to the alveolar surface. B, Axial CT image shows a bony cleft (arrow) between the left central and lateral maxillary incisors. C, Coronal CT image shows the extension of the bony clefting (arrow) to involve the primary palate.
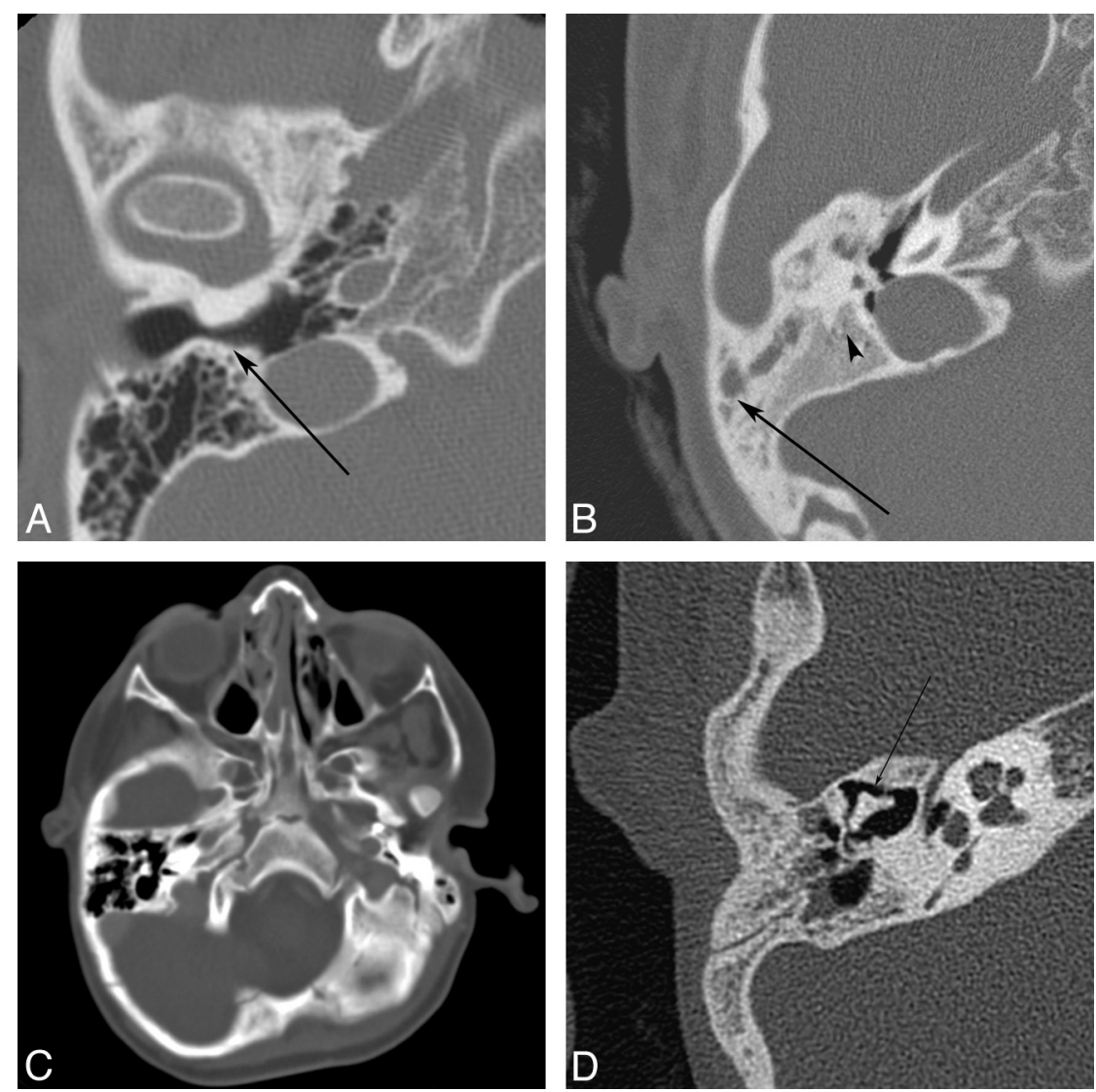

Fig 5. Auricular atresia in various degrees of severity. $A$, Axial CT image in a 64-year-old woman with nonsyndromic EAC atresia shows marked narrowing of the bony EAC (arrow). $B$, Axial CT image in a 9-year-old girl shows severe atresia with a lateral bony plate (arrow). The middle ear cavity is small and dysplastic (arrowhead). There is also ipsilateral microtia. C Axial CT image in a 3-year-old boy with Goldenhar syndrome shows complete bony atresia of the right EAC. D, Axial CT image in a 6-year-old boy with unilateral auricular atresia with associated ossicular chain fusion (arrow) and microtia (not shown).

tected by using high-resolution postnatal sonography, ${ }^{22}$ to grossly visible clefts involving skin, muscle, and bone.

Radiologic evaluation of facial clefting should focus on searching for primary defects of the lips and palate and then proceed in a systematic fashion to associated defects (Fig 4). Sonography can be used to identify clefting prenatally in the lip and primary palate (anterior alveolar ridge). Prenatally identifying a cleft in the secondary palate or an isolated cleft palate is difficult and virtually impossible with older equip- ment. Thus, the role of careful postnatal clinical evaluation remains vital. CT evaluation of facial clefting is typically reserved for complex cases and those with defects or complications outside the lip and palate.

\section{Auricular Atresia}

Auricular atresia occurs along a spectrum from an isolated malformed auricle to, at the most extreme form, an absent EAC with severe inner, middle, and external ear defects. These 

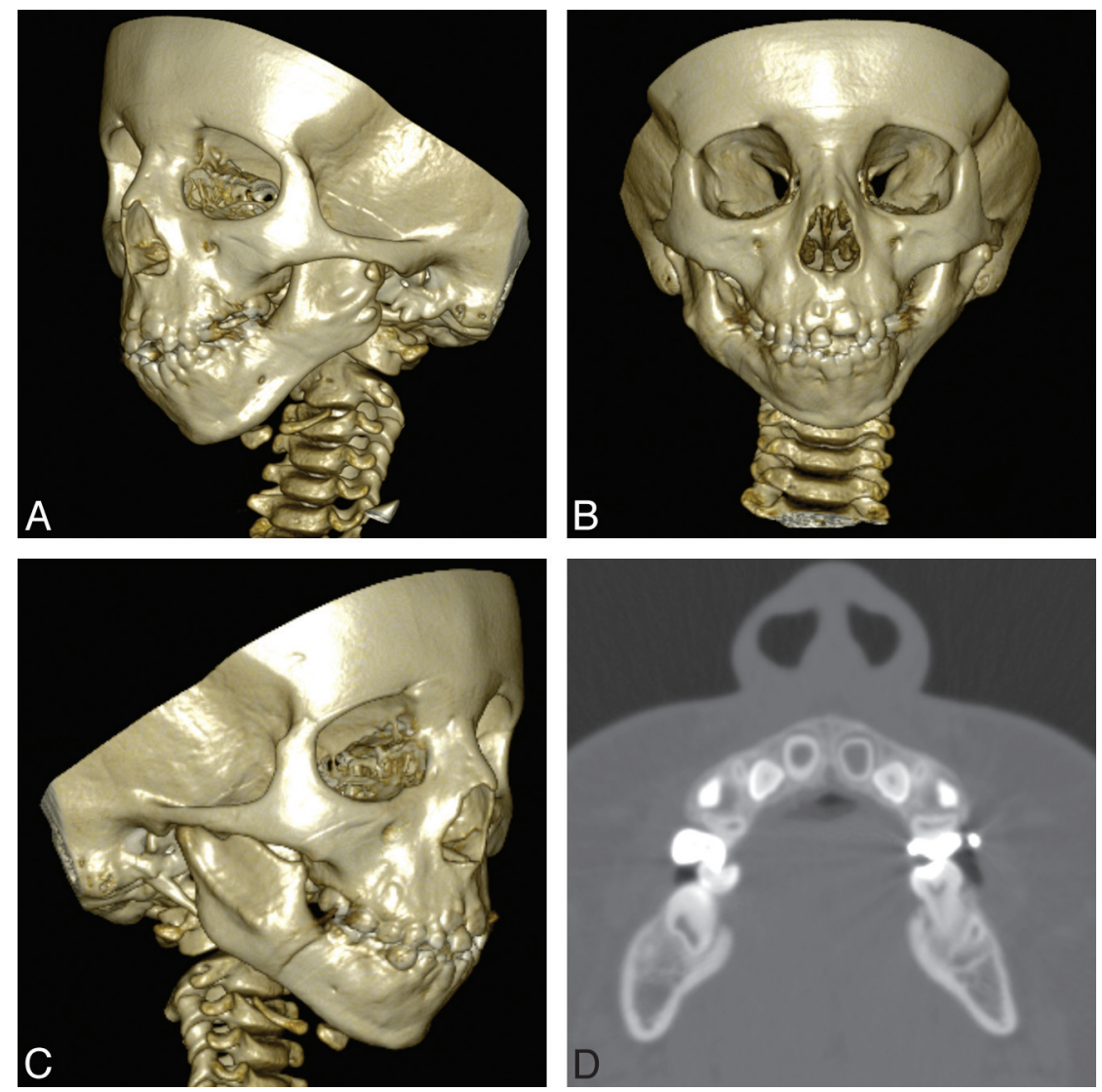

Fig 6. A 6-year-old boy with syndromic micrognathia. $A-C, 3 D$ bony reconstructions show mandibular hypoplasia and abnormal temporomandibular joints, condyles, and coronoid processes $D$, Axial CT image shows severe micrognathia and malocclusion.

severe cases of EAC atresia are sometimes associated with a bony plate that replaces the tympanic ring and forms the lateral wall of the dysplastic middle ear cavity. Due to the common embryologic origin, EAC abnormalities are often associated with abnormalities of the external and middle ear. Middle ear defects can be subtle or severe and include absent or maldevelopment of any of the ossicles, with alteration of other structures of common embryologic origin (such as the course of the facial nerve) (Fig 5). ${ }^{12,31-33}$

Jahrsdoerfer et $\mathrm{al}^{34}$ described a 10 -point rating scale for the selection of surgical candidates by comparing high-resolution CT findings with postsurgical hearing results. Using 9 reproducible criteria, one calculates a score to predict postoperative

$\begin{aligned} & \text { Table 2: System of Jahrsdoerfer et al for preoperative evaluation of } \\
& \text { aural atresia and stenosis as assessed using high-resolution CT of } \\
& \text { the temporal bone }\end{aligned}$
\begin{tabular}{lccl} 
Parameter & Points & Score & Candidate \\
\hline Stapes present & 2 & 10 & Excellent \\
Oval window & 1 & 9 & Very good \\
Round window & 1 & 8 & Good \\
Middle ear space & 1 & 7 & Regular \\
Mastoid pneumatization & 1 & 6 & Borderline \\
Facial nerve course & 1 & $\leq 5$ & Poor \\
Malleus-incus complex & 1 & & \\
Incus-stapes articulation & 1 & & \\
Auricle appearance & 1 & & \\
\hline
\end{tabular}

a The percentage of successful surgeries corresponds roughly with the rating scale (ie, score of 8 equals approximately $80 \%$ chance of postoperative hearing at normal or near-normal levels). Adapted from Jahrsdoerfer et al, 1992. ${ }^{34}$ improvement of the speech-reception threshold (Table 2). The criteria include assessment of the stapes, oval window, round window, middle ear space, mastoid pneumatization, facial nerve course, malleus-incus complex, and incus-stapes articulation. One point is given for each item with a normal or slightly dysplastic appearance. The stapes is an exception, for which 2 points are given when present. The final point is based on the clinical appearance of a fairly developed auricle. Patients with $\geq 6$ points on the grading system are considered possible candidates for surgical reconstruction. This method has demonstrated clinical utility and also provides a useful evaluation system for the radiologist and otologist. The proper use of this rating scale relies on the availability of high-quality CT examinations and radiologists with detailed knowledge of the relevant anatomy.

Auricular atresia can produce a number of problems for patients, including audiologic, cosmetic, and other associated clinical problems. ${ }^{12}$ EAC atresia has been described as part of various syndromes including TCS, ACS, PRS as well as Goldenhar, Crouzon, Möbius, Klippel-Feil, Fanconi, VCFS, Vater, and CHARGE syndromes. ${ }^{35}$

\section{Micrognathia}

Micrognathia is a frequently encountered facial abnormality in which the mandible is hypoplastic. Micrognathia is largely associated with craniofacial syndromes; however, nonsyndromic cases do arise. A study by Singh and Bartlett ${ }^{36}$ showed that of 266 patients with micrognathia, only 18 had congenital 
micrognathia without an identified syndrome. Micrognathia can be accompanied by the full spectrum of PRS (micrognathia, cleft palate, and relative macroglossia) and is also a dominant feature in ACS, HFM, TCS, and Stickler syndrome. It may also be seen variably in VCFS. ${ }^{17}$

Milder forms of micrognathia are common in infants and typically resolve with growth of the mandible. Radiologic evaluation of micrognathia should focus on the degree of mandibular hypoplasia, the temporomandibular joint, and the condyle and coronoid processes. One should also look for the often-associated abnormalities of the auricle, maxilla, and palate. Micrognathia is typically associated with malocclusion (abnormal tooth alignment), which may require orthodontic treatments and/ or tooth extraction. Preoperative CT evaluation is important for surgical planning and postoperative assessment of improvement (Fig 6).

In syndromes involving micrognathia, the oromandibular abnormalities often require the most intensive medical intervention. In severe cases of mandibular hypoplasia, glossoptosis may lead to upper respiratory tract obstruction, with mortality as high as $30 \%$, due to the combined effects of malnutrition, airway obstruction, and failure to thrive. ${ }^{37,38}$ General anesthesia can be problematic due to problems with intubation. Glossoptosis is also associated with snoring, apnea, and sleep disturbance. In less severe cases, malocclusion may lead to masticatory abnormalities that require orthodontic treatment or orthognathic surgery. Speech therapy may also be required to treat the articulation defects that may be seen in some patients. Microsomia and limited mandibular excursion can produce difficulty with intraoral examinations and treatments that require intraoral manipulation.

\section{Conclusions}

The first and second BAs are the embryologic origin of many of the structures of the face. A wide variety of congenital conditions may arise from their contents. A knowledge of the anatomic formation of this region is important in understanding abnormalities in development, which in turn aids in the formulation of precise diagnoses and differential diagnostic considerations.

\section{Acknowledgments}

We thank Michael Cunningham, MD, $\mathrm{PhD}$, for his assistance with manuscript preparation.

\section{References}

1. Marsh JL. Comprehensive Care for Craniofacial Deformities. St. Louis: Mosby; 1985

2. Passos-Bueno MR, Ornelas CC, Fanganiello RD. Syndromes of the first and second pharyngeal arches: a review. Am J Med Genet A 2009;149A:1853-59

3. Walker MB, Trainor PA. Craniofacial malformations: intrinsic vs extrinsic neural crest cell defects in Treacher Collins and 22q11 deletion syndromes. Clin Genet 2006;69:471-79

4. Trainor PA, Dixon J, Dixon MJ. Treacher Collins syndrome: etiology, pathogenesis and prevention. Eur J Hum Genet 2009;17:275-83

5. Moraes F, Novoa A, Jerome-Majewska LA, et al. Tbxl is required for proper neural crest migration and to stabilize spatial patterns during middle and inner ear development. Mech Dev 2005;122:199-212

6. Castillo M. Congenital abnormalities of the nose: CT and MR findings. AJR Am J Roentgenol 1994;162:1211-17

7. Sadler TW, Langman J. Langman's Medical Embryology. 10th ed. Philadelphia: Lippincott Williams \& Wilkins; 2006;xiii, 371

8. Maran AG, Buchanan DR. Branchial cysts, sinuses and fistulae. Clin Otolaryngol Allied Sci 1978;3:77-92

9. Stone JA, Figueroa RE. Embryology and anatomy of the neck. Neuroimaging Clin N Am 2000;10:55-73, viii

10. Larsen WJ. Human Embryology. New York: Churchill Livingstone; 1993

11. Waldhausen JH. Branchial cleft and arch anomalies in children. Semin Pediatr Surg 2006;15:64-69

12. Kosling S, Omenzetter M, Bartel-Friedrich S. Congenital malformations of the external and middle ear. Eur J Radiol 2009;69:269-79

13. Rodriguez K, Shah RK, Kenna M. Anomalies of the middle and inner ear. Otolaryngol Clin North Am 2007;40:81-96, vi

14. Osumi-Yamashita N, Ninomiya Y, Eto K. Mammalian craniofacial embryology in vitro. Int J Dev Biol 1997;41:187-94

15. Benson MT, Dalen K, Mancuso AA, et al. Congenital anomalies of the branchial apparatus: embryology and pathologic anatomy. Radiographics 1992;12:943-60

16. Arosarena OA. Cleft lip and palate. Otolaryngol Clin North Am 2007;40:27-60, vi

17. Som PM, Curtin HD. Head and Neck Imaging. St. Louis: Mosby; 2003

18. Sandham A, Nelson R. Embryology of the middle third of the face. Early Hum Dev 1985;10:313-15

19. Barkovich AJ, Vandermarck P, Edwards MS, et al. Congenital nasal masses: CT and MR imaging features in $\mathbf{1 6}$ cases. AJNR Am J Neuroradiol 1991;12:105-16

20. Kennard CD, Rasmussen JE. Congenital midline nasal masses: diagnosis and management. J Dermatol Surg Oncol 1990;16:1025-36

21. Moore KL. Before We Are Born: Basic Embryology and Birth Defects. Philadelphia: Saunders; 1989

22. Weinberg SM, Brandon CA, McHenry TH, et al. Rethinking isolated cleft palate: evidence of occult lip defects in a subset of cases. Am J Med Genet A 2008;146A:1670-75

23. Gorlin RJ, Cervenka J, Pruzansky S. Facial clefting and its syndromes. Birth Defects Orig Artic Ser 1971;7:3-49

24. Strong EB, Buckmiller LM. Management of the cleft palate. Facial Plast Surg Clin North Am 2001;9:15-25, vii

25. Ghassibe M, Bayet B, Revencu N, et al. Orofacial clefting: update on the role of genetics. B-Ent 2006;2(suppl 4):20-24

26. Benacerraf BR, Mulliken JB. Fetal cleft lip and palate: sonographic diagnosis and postnatal outcome. Plast Reconstr Surg 1993;92:1045-51

27. Stanier P, Moore GE. Genetics of cleft lip and palate: syndromic genes contribute to the incidence of non-syndromic clefts. Hum Mol Genet 2004;13(spec no 1):R73-81. Epub 2004 Jan 13

28. Storm AL, Johnson JM, Lammer E, et al. Auriculo-condylar syndrome is associated with highly variable ear and mandibular defects in multiple kindreds. Am J Med Genet A 2005;138:141-45

29. Lidral AC, Moreno LM, Bullard SA. Genetic factors and orofacial clefting. Semin Orthod 2008;14:103-14

30. Melnick M. Cleft lip and cleft palate: etiology and pathogenesis. In: Kernahan DA, Rosenstein SW, Dado DV, eds. Cleft Lip and Palate: A System of Management. Baltimore: Williams \& Wilkins; 1990:3-12

31. Fatterpekar GM, Doshi AH, Dugar M, et al. Role of 3D CT in the evaluation of the temporal bone. Radiographics 2006;26(suppl 1):S117-32

32. Gassner EM, Mallouhi A, Jaschke WR. Preoperative evaluation of external auditory canal atresia on high-resolution CT. AJR Am J Roentgenol 2004;182:1305-12

33. Yeakley JW, Jahrsdoerfer RA. CT evaluation of congenital aural atresia: what the radiologist and surgeon need to know. J Comput Assist Tomogr 1996;20:724-31

34. Jahrsdoerfer RA, Yeakley JW, Aguilar EA, et al. Grading system for the selection of patients with congenital aural atresia. Am J Otol 1992;13:6-12

35. Schuknecht HF. Congenital aural atresia. Laryngoscope 1989;99:908-17

36. Singh DJ, Bartlett SP. Congenital mandibular hypoplasia: analysis and classification. J Craniofac Surg 2005;16:291-300

37. Caouette-Laberge L, Bayet B, Larocque Y. The Pierre Robin sequence: review of 125 cases and evolution of treatment modalities. Plast Reconstr Surg 1994;93:934-42

38. van den Elzen AP, Semmekrot BA, Bongers EM, et al. Diagnosis and treatment of the Pierre Robin sequence: results of a retrospective clinical study and review of the literature. Eur J Pediatr 2001;160:47-53 